\title{
Preselection and response biasing in short-term motor memory
}

\author{
GEORGE E. STELMACH, J. A. SCOTT KELSO, and PENNY DORRANCE McCULLAGH \\ Motor Behavior Laboratory, Department of Physical Education, University of Wisconsin, Madison, Wisconsin 53706
}

\begin{abstract}
Two experiments were performed comparing preselected (subject defined) and constrained (experimenter defined) movements. In the first experiment, subjects made reproduction responses immediately or under unfilled and filled 15-sec retention intervals. Results indicated that recall of preselected movements was clearly superior until the interpolation of information processing activity. In addition, preselected movements demonstrated no forgetting over a 15 -sec retention interval while constrained movements evidenced spontaneous memory loss, suggesting that preselected movements possess a stronger representation in memory. The second experiment examined this interpretation in a response biasing paradigm. Subjects made criterion responses under preselected or constrained conditions, while the interpolated movement was always in the constrained mode and \pm 40 deg from the criterion. The subjects' task was to attend to both movements and recall each when instructed. While preselected recall was clearly superior to constrained recall, response biasing was clearly evident in both. The failure to find differential biasing effects was discussed in terms of the relative trace strength hypothesis (Stelmach \& Walsh, 1972).
\end{abstract}

A plethora of cues are potentially available to aid in the reproduction of movement. Information regarding direction, velocity, acceleration and position can be encoded by peripheral receptor mechanisms (see Smith, 1969 , for review). In addition, it is thought that central mechanisms, by storing specific efferent commands to the muscles, can provide an adequate basis for accurate localization (Festinger \& Canon, 1965). Implicit here is the contention that the organism is capable of adjusting efferent commands to the motoneurons in proportion to the requirements of the expected localization response. Thus, for this information to be useful, the subject must know the goal of his movement in advance.

Typically, the motor memory paradigm requires the blindfolded subject to reproduce a movement whose mode of presentation is to an experimenter defined stop. In this situation, the subject must be primarily dependent on proprioceptive information as a basis for accurate recall, since prior knowledge of the movement endpoint is absent. Hence, for the movement presentation, the subject is incapable of generating an accurate series of efferent commands, a record of which could prove useful to resist memory loss (Jones, 1974).

The first experiment compared preselected (subject defined) and constrained (experimenter defined) movements in an attempt to examine the importance of "preset" movement control. A recent study by Marteniuk (1973) suggests that the two modes of

This researcli was supported by Research Grant MH 22081-01 from the National Institute of Mental Health, by the Graduate School of the University of Wisconsin, Project No. 150433, and by the National Institute of Education, Grant NE-G-00-3-009, awarded to the first author. However, the opinions expressed herein do not necessarily represent the position or policy of the National Institute of Education, and no official endorsement by the National Institute of Education should be inferred. Requests for reprints should be sent to Georde $\mathrm{E}$. Stelmach, Motor Behavior Laboratory, University of Wisconsin, 2000 Observatory Drive, Madison, Wisconsin 53706. movement presentation may result in differential memory representation. Unique to the latter investigation was the fact that the subject had comple te information about the movement extent and location prior to making his response. In contrast to previous studies of constrained movements (Laabs, 1973; Marteniuk \& Roy, 1972) which postulated different storage modes for distance and location information, it was found that both sources of information had access to central representation, since no forgetting occurred until the interpolation of information processing activity. In addition, and in direct contrast to Laabs' (1973) model of short-term motor memory (STMM), Marteniuk (1973) reported that variable error (VE) failed to index trace decay or differentiate movement cues in STMM. It may well be that these differential findings have occurred as a result of preselected movements being represented in memory differently than movements terminated by a stop. This position has been adopted by Jones $(1972,1974)$ using a task in which the subjects were instructed to move "as quickly as possible". Only preselected movements were well retained over a short-term interval, while constrained movements decayed spontaneously and we re not subject to interference from interpolated verbal activity.

Clearly, if preselected movements result in superior recall it may be postulated that they possess a stronger representation in memory. As such they may provide a means of examining the locus of response biasing effects in STMM (Laabs, 1973; Pepper \& Herman, 1970). Typically, when a movement differing from the criterion is presented during the retention interval, recall error is shifted in the direction of the interpolated movement. The magnitude of the biasing effect has been shown to be dependent on the amplitude of the interpolated movement (Craft \& Hinrichs, 1971), the duration of 
time spent at the interpolated location (Stelmach \& Walsh, 1972) and the temporal occurrences of interpolated activity within the retention interval (Stelmach \& Walsh, 1973). Recent data indicate that the effect of biasing can be reduced when the criterion memory trace is strengthened, for example, by repetition and heightened feedback (Stelmach \& Kelso, 1975). The foregoing findings have been interpreted in terms of a relative trace strength hypothesis, originally postulated by Stelmach and Walsh (1972).

The second experiment was, therefore, designed to examine the relative trace strength hypothesis for preselected and constrained movements. In the paradigm employed, the criterion movement (CM) was made under either preselected or constrained conditions while the biasing movement (BM) was always made in the constrained mode. On the basis of the relative trace strength hypothesis, a reduction in response biasing would be predicted in the preselected-constrained, CM-BM combination relative to a constrained-constrained condition.

\section{EXPERIMENT I}

\section{Method}

Subjects. Right-handed male and female subjects $(N=36)$ were recruited from the University of Wisconsin campus and paid $\$ 2.00$ for their participation. The subjects were systematically assigned to one of two experimental conditions (preselected or constrained) in an alternating order, with caution taken to equate for sex in the two groups.

Apparatus. The lever apparatus employed in the present investigation has been described in detail elsewhere (Stelmach \& Walsh, 1972). The apparatus allowed for frictionless movements ranging from $0 \mathrm{deg}$ on the right to $170 \mathrm{deg}$ on the left. A box-like structure surrounded the apparatus, shielding the subject and the experimenter from direct view, and in addition restricted the subject from viewing his right hand during the slow positioning response. The subject sat in a straight-backed chair located centrally in front of the apparatus, and head position was stabilized throughout the experiment by a chin rest

Procedure. All subjects were given a brief familiarization period on the lever apparatus in which the complete range of movement $(0-170 \mathrm{deg})$ was presented. Subjects were instructed to move the lever smoothly and continuously throughout all trials.

For preselected movements, the subjects were instructed to "Select" the location and extent of their movement approximately $2 \mathrm{sec}$ before the command "Move" was issued. The importance of preselection was clearly stressed with the additional request that the subject should attempt to disperse his movements evenly throughout the entire range, making an equal number of short, medium-short, medium-long, and long movements. When the criterion movement (CM) was completed, the subject announced "There" and remained at this location for $2 \mathrm{sec}$ until told to "Return" to the starting position $(0 \mathrm{deg})$. Subjects were instructed to "Recall" their initial displacement as accurately as possible after the retention interval manipulation.

The immediate recall condition required subjects to estimate the initial movement on their immediate return to the starting position. In the unfilled retention interval, subjects were instructed to "Rehearse" the extent and end location of their initial displacement for $15 \mathrm{sec}$ before the command "Recall" was issued. This procedure was intended to insure that the subject concentrated on the criterion movement as opposed to merely resting at the starting position. Filled retention interval trials $(15 \mathrm{sec})$ required the subjects to count backwards in threes as quickly and accurately as possible from a 3 -digit number which was immediately announced aloud by the experimenter on completion of the initial displacement. Each subject received 20 trials under each retention interval condition with the order of presentation being systematically rotated among subjects. For all retention interval conditions a 15 -sec intertrial interval ensued between beginning of reproduction and the onset of the next trial.

To insure an identical dispersion of movements between groups, each subject in the constrained condition was "yoked" to a preselected subject, i.e., each subject in the constrained condition made the same $\mathrm{CMs}$ as his counterpart in the preselected condition. Instructions were similar to the aforementioned condition with the omission of a command to "Select." Rather, subjects were instructed to "Move" to a peg stopper attending to both the extent and end location of their movement. After remaining at the stop for $2 \mathrm{sec}$, subjects returned to the starting position and received identical commands to those previously described for the retention interval manipulations.

Design. A 2 by 3 by 4 independent groups (preselected and constrained) design was utilized with repeated measures on the last two factors (retention intervals and sectors). The subjects' movements under each retention interval condition (immediate, filled, and unfilled) were categorized into one of four sectors $(0-40,41-80,81-120,121-160 \mathrm{deg})$ on a post hoc basis. For the purpose of analysis, errors in each sector were collapsed for constant (CE) and absolute error (AE) inspection. In addition, a measure of within-sector consistency (VE') was obtained by calculating the standard deviation around the subject's mean $C E$ within a sector. It should be noted that previous procedures in STMM have been to obtain several estimations of a single target location predetermined by the experimenter. The VE is then defined as the standard deviation around the mean constant error. In the present study, however, since the subject was allowed to preselect his own targets, such a measure was not possible. The index $V E^{\prime}$ was therefore adopted in an attempt to determine the consistency of the subject's performance over a wide range of movement.

\section{Results}

Before analyzing recall errors, it was of interest to examine the dispersion of movements within each sector for two reasons. First it was important to insure that the subject distributed his movements evenly within a particular retention interval condition; and secondly, to ascertain if subjects differed in their movement dispersions across retention interval conditions. A 3 by 4 (retention intervals by sector) analysis of variance was performed on responses within a sector and across retention intervals. Neither the main effects of retention intervals $[F(2 / 204)<1]$, sectors $[F(3 / 204)<1]$, nor the interaction $[F(6 / 204)=1.95, p>.05]$ were significant.

The means and standard errors of the main effect of groups, retention intervals, and sectors are presented in Table 1. While the main effect of CE for groups was not significant $[F(1 / 34)=2.98, p>.05]$, both $\mathrm{VE}^{\prime}$ and $\mathrm{AE}$ were significant, $[F(1 / 34)=16.13]$ and $[F(1 / 34)=27.89, p<.011$, respectively, reflecting the 
clear superiority at recall of preselected over constrained movements.

The main effect of sectors was significant for all dependent variables $[F(3 / 102)=13.94,3.56$, and 11.26 , $\mathrm{p}<.05$, for $\mathrm{CE}, \mathrm{AE}$, and $\mathrm{VE}^{\prime}$, respectively]. For $\mathrm{CE}$ only Sector 1 was significantly different from Sector 2, while for $V^{\prime}$ Sector 1 was significantly different from Sectors 2 and 4. For $\mathrm{AE}$ there were no detectable differences using Tukey's H.S.D. test in spite of the significant $\mathrm{F}$.

The main effect of retention intervals was also significant for all three dependent variables $[\mathrm{F}(2 / 68)=5.39,62.70$, and $70.81, \mathrm{p}<.01$, respectively, for $\mathrm{CE}, \mathrm{AE}$, and $\mathrm{VE}^{\prime}$. The main effect for $\mathrm{CE}$ was subjected to post hoc analysis of means since it was the only dependent measure that failed to evidence a significant Groups by Retention Intervals interaction. Using Tukey's test, significant differences in $\mathrm{CE}$ were revealed between unfilled and filled retention interval conditions.

Of dominant interest to the present study was the Groups by Retention Intervals interaction since earlier discussion indicated that constrained and preselected movements may have differential retention characteristics. While this interaction was not significant for $\mathrm{CE}$, both $\mathrm{AE}[\mathrm{F}(2 / 68)=17.69]$ and $\mathrm{VE}^{\prime}$ $[F(2 / 68)=7.86]$ were significant at the .01 level. A simple effects analysis on $\mathrm{AE}$ revealed that constrained and preselected movements were significantly different under immediate and unfilled retention intervals, reflecting the clearly superior performance of the preselected group. However, when interpolated information reduction activity was introduced, there were no differences between groups. To more clearly establish whether the individual groups evidenced behavioral differences over retention interval conditions, post hoc analysis was undertaken on the interaction means (see Table 1). For constrained movements a significant increase in $\mathrm{AE}$ occurred between immediate and unfilled retention interval recall while there was no further effect of filling the retention interval with interpolated processing activity. On the other hand, with preselected movements no increases in $\mathrm{AE}$ were evident until the subject was required to perform processing activity during the retention interval. The findings for $\mathrm{VE}^{\prime}$, while mirroring those for $\mathrm{AE}$ very closely, differed only in that a significant increase cccurred for constrained recall with the processing activity. In addition, a Groups by Sector interaction $[F(3 / 102)=3.43, p<.05]$ and a Retention Interval by Sector interaction $[F(6 / 204)=10.23, p<.01]$ were found for CE only.

\section{EXPERIMENT II}

\section{Method}

Subjects. The subjects were 32 male volunteers from the University of Wisconsin. The subjects were systematically
Table 1

Means (in Degrees) and Standard Errors of the Mean for Groups, Retention Intervals, and Sectors

\begin{tabular}{|c|c|c|c|c|c|c|}
\hline \multirow{2}{*}{$\begin{array}{l}\text { Main } \\
\text { Effects }\end{array}$} & \multicolumn{3}{|c|}{ Preselected } & \multicolumn{3}{|c|}{ Constrained } \\
\hline & $\mathrm{CE}$ & $\mathrm{AE}$ & $\mathrm{VE}^{\prime}$ & $\mathrm{CE}$ & $\mathrm{AE}$ & $\mathrm{VE}^{\prime}$ \\
\hline
\end{tabular}

Groups

$\begin{array}{lrrrrrr}M & .60 & 4.05 & 4.00 & -.86 & 6.00 & 5.04\end{array}$

Retention Intervals (Sec)

$\begin{array}{llrrrrrr}0 & \mathrm{M} & .77 & 2.69 & 2.63 & -.83 & 4.79 & 4.00 \\ & \mathrm{SE} & .47 & .23 & .24 & 1.06 & .57 & .34 \\ 15 & \mathrm{M} & -.27 & 3.07 & 3.37 & -1.86 & 6.46 & 5.11 \\ \text { (Unfilled) } & \mathrm{SE} & .48 & .28 & .33 & 1.39 & .69 & .52 \\ 15 & \mathrm{M} & 1.31 & 6.39 & 6.01 & .11 & 6.75 & 6.01 \\ \text { (Filled) } & \mathrm{SE} & 1.00 & .52 & .62 & 1.36 & .76 & .62\end{array}$

Sectors (Deg)

\begin{tabular}{rlrrrrrr}
$0-40$ & $\mathrm{M}$ & 2.35 & 4.02 & 3.27 & .98 & 5.52 & 3.96 \\
& $\mathrm{SE}$ & .59 & .34 & .33 & 1.17 & .63 & .43 \\
$41-80$ & $\mathrm{M}$ & .21 & 4.43 & 4.43 & -3.54 & 6.92 & 5.34 \\
& $\mathrm{SE}$ & .81 & .37 & .38 & 1.51 & .89 & .46 \\
$81-120$ & $\mathrm{M}$ & .86 & 3.77 & 4.16 & .78 & 5.35 & 4.93 \\
& $\mathrm{SE}$ & .60 & .32 & .43 & 1.17 & .59 & .51 \\
$121-160$ & $\mathrm{M}$ & -1.01 & 3.98 & 4.16 & -1.66 & 6.21 & 5.94 \\
& $\mathrm{SE}$ & .59 & .35 & .42 & 1.20 & .57 & .57 \\
\hline
\end{tabular}

assigned in an alternating sequence to one of two experimental groups (preselected-constrained or constrained-constrained).

Apparatus. The lever apparatus was identical to that employed in Experiment $\mathrm{I}$.

Procedure. Twenty control trials constituted one phase of the experiment. Preselected and constrained movements were administered in the same manner as those in Experiment $\mathbf{I}$, with the exception that the movements ranged between 60 and $120 \mathrm{deg}$. This restriction was essential so that control trials would be directly comparable to biasing trials. During the $20-\mathrm{sec}$ retention interval, subjects were instructed to concentrate on the extent and end location of their movement.

For the 40 biasing trials, subjects in the preselected-constrained (pre-con) condition were free to make their initial displacement of any length and to any endpoint within the 60-120 deg range. Subjects received the same commands of "Select" and "Move," and were instructed to disperse their movements throughout this range. After returning to the starting position from the initial preselected movement subjects rested at the stop until instructed to "Move" $10 \mathrm{sec}$ later to a constrained location. A peg stopper defined the end location of the BM and was either + or $40 \mathrm{deg}$ from the CM location. The direction of the BM was determined according to a random schedule. However, if subjects returned within a 2 -deg bandwidth of a previously selected location, the interpolated movement was in the opposite direction. Therefore, over the duration of the experiment subjects received approximately an equal number of positive and negative biasing trials. Subjects were required to recall both movements $20 \mathrm{sec}$ after their criterion movement had been completed.

In order to insure an identical dispersion of movements each subject in the constrained-constrained (con-con) condition was yoked to a subject in the pre-con group; that is, each constrained movement was identical to the previous preselected subject's displacements. Instructions in the con-con condition were identical to pre-con except for the omission of a "Select" command. The order of control and biasing trials was counterbalanced in each condition.

Design. $A 2$ by 3 by 4 mixed factorial design was employed for criterion recall. The first factor (pre-con vs. con-con) was a between-subject factor while the repeated measures factors of 
Table 2

$\begin{aligned} & \text { Means (in Degrees) and Standard Errors of the Mean } \\ & \text { for Groups, Biasing Direction, and Sectors for } \\ & \text { Recall of the Crtierion Movement }\end{aligned}$
\[ \begin{array}{c}\text { PRE-CON } \\ \mathrm{CE} A \mathrm{AE} \quad \mathrm{VE}^{\prime}\end{array} \]

Groups

\begin{tabular}{|c|c|c|c|c|c|c|c|}
\hline & $\begin{array}{l}M \\
\text { SE }\end{array}$ & $\begin{array}{l}.01 \\
.66\end{array}$ & $\begin{array}{r}3.82 \\
61\end{array}$ & $\begin{array}{r}3.89 \\
.48\end{array}$ & $\begin{array}{r}1.10 \\
92\end{array}$ & $\begin{array}{r}5.68 \\
.61\end{array}$ & $\begin{array}{r}5.73 \\
.73\end{array}$ \\
\hline \multicolumn{8}{|c|}{ Biasing Direction } \\
\hline Positive & $\begin{array}{l}\mathrm{M} \\
\mathrm{SE}\end{array}$ & $\begin{array}{r}1.81 \\
.63\end{array}$ & $\begin{array}{r}3.99 \\
.49\end{array}$ & $\begin{array}{r}4.06 \\
.50\end{array}$ & $\begin{array}{r}3.58 \\
.87\end{array}$ & $\begin{array}{r}6.62 \\
.68\end{array}$ & $\begin{array}{r}6.25 \\
.95\end{array}$ \\
\hline Negative & $\begin{array}{l}\mathrm{M} \\
\mathrm{SE}\end{array}$ & $\begin{array}{r}-.48 \\
.71\end{array}$ & $\begin{array}{r}3.84 \\
.55\end{array}$ & $\begin{array}{r}4.10 \\
.47\end{array}$ & $\begin{array}{l}.10 \\
.94\end{array}$ & $\begin{array}{r}5.39 \\
.59\end{array}$ & $\begin{array}{r}5.84 \\
.67\end{array}$ \\
\hline Control & $\begin{array}{l}\mathrm{M} \\
\mathrm{SE}\end{array}$ & $\begin{array}{r}-1.31 \\
.63\end{array}$ & $\begin{array}{r}3.62 \\
.39\end{array}$ & $\begin{array}{r}3.52 \\
.47\end{array}$ & $\begin{array}{r}-.39 \\
.89\end{array}$ & $\begin{array}{r}5.04 \\
.55\end{array}$ & $\begin{array}{r}5.09 \\
.57\end{array}$ \\
\hline
\end{tabular}

Sectors (Deg)

$\begin{array}{llllllll}60-75 & M & -1.57 & 4.11 & 4.04 & -3.30 & 6.29 & 6.21\end{array}$

$\begin{array}{rrrrrrr}\text { SE } & .75 & .47 & .52 & 1.04 & .72 & .68\end{array}$

$\begin{array}{llllllll}76-90 & \mathrm{M} & -.41 & 3.00 & 3.30 & 1.26 & 4.55 & 4.85\end{array}$

$\begin{array}{llllllll}\mathrm{SE} & .52 & .34 & .37 & .77 & .48 & .63\end{array}$

$\begin{array}{rrrrrrrr}91-105 & \mathrm{M} & .86 & 3.77 & 3.92 & 2.93 & 5.86 & 5.80\end{array}$

$\begin{array}{rlrrrrrrr} & \text { SE } & .43 & .42 & .50 & .82 & .61 & .73 \\ 106-120 & \mathrm{M} & 1.15 & 4.38 & 4.31 & 3.49 & 6.03 & 6.05 \\ & \text { SE } & .94 & .67 & 53 & .96 & .62 & .89\end{array}$

biasing direction (positive vs. negative vs. control) and sectors were within-subjects manipulations. The design for biasing recall ( 2 by 2 by 4 ) was identical except for the omission of the 20 control trials. Subjects' movements were categorized on a post hoc basis into four sectors $(60-75,76-90,91-105,106-120 \mathrm{deg})$. For data analysis, errors in each sector were collapsed for constant error (CE), absolute error (AE), and within-sector consistency (VE').

\section{Results}

In order to insure that subjects in the preselected condition were dispersing their movements across the entire range available, a 3 by 4 (biasing direction by sectors) analysis of variance was performed on the response frequencies within each sector. Neither the main effects of biasing direction $[F(2 / 180)<1]$ nor the Biasing Direction by Sector interaction $[F(6 / 180)=1.15]$ were significant. Post hoc analysis of the sector main effect $[F(3 / 180)=10.85, p<.01]$ revealed significantly more responses in Sector 1 $(M=5.71)$ than in Sector $2(M=5.02), 3(M=4.92)$, or $4(M=4.42)$. In addition, Sector 2 had significantly more responses than Sector 4.

The means and standard errors of criterion recall responses for groups, biasing direction, and sectors are presented in Table 2. The main effect of groups was significant for $\mathrm{CE}, \mathrm{AE}$, and $\mathrm{VE}^{\prime}$, revealing the clear superiority of preselected over constrained recall, thus supporting the findings of Experiment I.

The main effect of biasing direction was significant for all three sources of error, $[F(2 / 60)=50.59,6.69$, and $4.17, \mathrm{p}<.05$ for $\mathrm{CE}, \mathrm{AE}$, and $\mathrm{VE}^{\prime}$ respectively]
Post hoc analysis of the means indicated that positive trials were significantly different from negative and control triais for $\mathrm{CE}$ and $\mathrm{AE}$ while for $\mathrm{VE}^{\prime}$ only positive and control trials were significantly different.

The main effect of sectors was likewise significant for all three dependent measures, $[F(3 / 90)=28.25,8.47$, and $4.22, \mathrm{p}<.01$ for $\mathrm{CE}, \mathrm{AE}$, and $\mathrm{VE}^{\prime}$ respectively]. Post hoc analysis of the $C E$ means indicated that Sector 1 was significantly different from all other sectors and that Sector 2 was different from Sector 4. Inspection of $\mathrm{AE}$ means showed that there was significantly less error in Sector 2 than in any other sector while for $\mathrm{VE}^{\prime}$ there was less variability in Sector 2 than in Sectors 1 or 4.

The Groups by Biasing Direction interaction was nonsignificant $[F(2 / 60)=1.33,2.97$, and $<1$ for $C E$, $\mathrm{AE}$, and $\mathrm{VE}^{\prime}$ respectively. In addition, the Groups by Sector interaction was significant for $\mathrm{CE}$ $[\mathrm{F}(3 / 90)=5.54, \mathrm{p}<.01]$ but not for $\mathrm{AE}$ or $\mathrm{VE}^{\prime}$ $(F<1)$, whereas the Biasing Direction by Sector interaction was significant for $\mathrm{AE}$ and $\mathrm{VE}^{\prime}$ $[F(6 / 180)=6.82$ and 2.38, $\mathrm{p}<.05]$ but not for $\mathrm{CE}$ $[F(6 / 180)=1.06, p>.05]$.

The only meaningful comparison for biasing recall was between groups. It should be noted that for biasing recall both groups of subjects were recalling similarly presented constrained movements, which may account for the nonsignificant group main effect for all three dependent measures $(F<1)$.

\section{DISCUSSION}

The striking feature of the data in Experiment I was the clearly superior performance of the preselected condition. It might be suggested that in this situation the subject has precise information regarding the extent and terminal location of the movement while the subject in the constrained group must continually monitor all aspects of the ongoing movement. Marteniuk's (1973) findings, as well as those of the present study, demonstrate no forgetting under preselected conditions until the interpolation of central processing activity. On the other hand, constrained movements decayed spontaneously over the $15-\mathrm{sec}$ retention interval and, in line with the AE data of Posner (1967) and Williams, Beaver, Spence, and Rundell (1969), showed no further effect of occupying the processing channel. The coupling of these two findings suggests that preselected movements are represented centrally to a greater degree than those of the constrained condition.

Although Laabs (1973) and Keele and Ells (1972) have provided evidence for proprioceptive location information requiring central processing capacity, Jones $(1972,1974)$ has argued, using a fast linear positioning task, that the primary mode of storage in STMM is the central monitoring of efferent commands (CME) to the muscles. The CME 
has been equated to the subject's ability to preset the movement extent and hence does not apply to constrained movements which are not thought to access central mechanisms (Jones, 1974). The present $\mathrm{AE}$ data on preselected movements appear to support the findings of Jones (1974). However, there is evidence that constrained movements also access central mechanisms, since interpolated verbal activity resulted in a significant increase in variability (see Table 1). Further support for this notion can be found in the Retention Interval by Sector interaction for $\mathrm{CE}$, where the constrained condition evidenced a clear dependence on central processing capacity for short movements. When interpolated processing activity was introduced the mean $\mathrm{CE}$ in the first sector for the filled interval was $4.68 \mathrm{deg}$, whereas the means for immediate and unfilled conditions were 0.11 and $-1.84 \mathrm{deg}$, respectively. Since interpolation of processing activity did affect constrained recall, the findings are contradictory to Jones (1974).

In addition to postulating different storage modes in STMM, Laabs' (1973) model has proposed VE as the most sensitive measure of trace decay. The first experiment, in support of Laabs (1973), clearly indicates that under constrained conditions, VE (or in this case $V E^{\prime}$ ) can give a fair approximation of trace decay. On the other hand, for preselected movements no increases in $\mathrm{VE}^{\prime}$ are evident, since the memory trace is presumably stable. This notion is further supported in the second experiment, where all three types of error revealed the superior recall accuracy of preselected movements.

On the other hand, Experiment II found response biasing effects for both preselected and constrained conditions, indicating that these movements were not differentially affected by interpolated movements in the constrained mode. This finding was unexpected and is contrary to the predictions of the relative trace strength hypothesis (Stelmach \& Walsh, 1972). An interesting feature of the data was that response biasing occurred primarily in a positive direction relative to control. As can be seen in Table 2, this effect can be readily explained by the predominantly negative response set in the control condition.
The findings of Experiment II are in agreement with recent data presented by Craft and Hinrichs (1971) and Craft (1973) which found response biasing uninfluenced by various experimental manipulations. For example, pre-cueing the subject prior to presentation of the movements as to which was to be recalled failed to reduce shifts in recall error (Craft, 1973; Craft \& Hinrichs, 1971). These findings suggest that response biasing may be subject to peripheral influences such as those arising from movement rather than any central interaction.

\section{REFERENCES}

Craft, J. L. A two-process theory for the short-term retention of motor responses. Journal of Experimental Psychology, 1973. 98, 196-202.

Craft, J. L., \& Hinrichs, J. V. Short-term retention of simple motor responses: Similarity of prior and succeeding responses. Journal of Experimental Psy chology, 1971, 87, 297-302.

Festinger, L., \& Canon, L. K. Information about spatial location based on knowledge about efference. Psychological Review, $1965,72,373-384$.

Jones, B. Outflow and inflow in movement duplication. Perception \& Psychophysics, $1972,12,95-96$.

Jones, B. Role of central monitoring of efference in short-term memory for movements. Journal of Experimental Psychology, $1974,102,37-43$.

Keele, S. W.. \& Ells, J. C. Memory characteristics of kinesthetic information. Journal of Motor Behavior, 1972, 4, 127-134.

Laabs, G. J. Cue effects in motor short-term memory. Journal of Experimental Psychology, 1973, 100, 168-177.

Marteniuk, R. G. Retention characteristics of motor short-term memory cues. Journal of Motor Behavior, 1973, 5, 249-259.

Marteniuk, R. G., \& Roy, E. A. The codability of kinesthetic location and distance information. Acta Psychologica, 1972, 36, 471-479.

Pepper, R. L., \& Herman, L. M. Decay and interference effects in short-term retention of a discrete motor act. Journal of Experimental Psychology, Monograph, 1970, 83, No. 2.

posner, M. I. Characteristics of visual and kinesthetic memory cues. Journal of Experimental Psy chology, 1967, 75, 103-107.

Smith, J. L. Kinesthesis: A model for movement feedback. In R. C. Brown \&. J. Cratty (Eds.). New perspectives of man in action. New Jersey: Prentice-Hall, 1969.

Stelmach, G. E., \& Kelso, J. A. S. Memory trace strength and response biasing in short-term motor memory. Memory \& Cognition, 1975, 3, 58-62.

Stelmach, G. E., \& Walsh, M. F. Response biasing as a function of duration and extent of positioning acts. Journal of Experimental Psy chology, 1972, 92, 354-359.

Stelmach, G. E., \& Walsh, M. F. The temporal placeme nt of interpolated movements in short-term memory. Journal of Motor Behavior, 1973,5, 165-173.

Williams, H. L., Beaver, W. S., Spence, M. T., \& Rundell, O. H. Digital and kinesthetic memory with interpolated information processing. Journal of Experimental Psychology, 1969, 80, 537-541.

(Received for publication February 3, 1975. Revision received April 18, 1975.) 